\title{
As-I (Arsenic-lodine)
}

\section{H. Okamoto}

The As-I phase diagram was missing in [Massalski2].

Figure 1 shows the As-I phase diagram determined by [1973Che] by means of DTA, x-ray diffraction, and metallography.

Earlier, [1968Rol] reported the existence of $\mathrm{AsI}_{2}$. However, this phase is metastable [1973Che].

The crystal structure of $\mathrm{AsI}_{3}$ was determined by [1965Tro] (Table 1).

\section{References}

1965Tro: J. Trotter, The Crystal Structure of Arsenic Triiodide, $\mathrm{AsI}_{3}$, Z. Kristallogr., 1965, 121, p 81-86

1968Rol: R.F. Rolsten, Iodine Metals and Metal Iodides, Izd. Metallurgiya, Moscow, 1968, p 387, as quoted in [1973Che]

1973Che: A.P. Chernov, S.A. Dembovskii, and A.F. Borisenkova, Equilibrium Diagram of the As-I System, Russ. J. Inorg. Chem., 1973, 18(10), p 1530-1531

Table 1 As-I crystal structure data

\begin{tabular}{lccccc}
\hline Phase & Composition, at.\% I & Pearson symbol & Space group & Strukturbericht designation & Prototype \\
\hline (As) & 0 & $h R 2$ & $R \overline{3} m$ & $A 7$ & $\alpha \mathrm{As}$ \\
$\mathrm{AsI}_{3}$ & 75 & $h R 24$ & $R \overline{3}$ & $\ldots$ & $\ldots$ \\
$(\mathrm{I})$ & 100 & $C C 8$ & $C m c a$ & $A 14$ & $\mathrm{I}$ \\
\hline
\end{tabular}

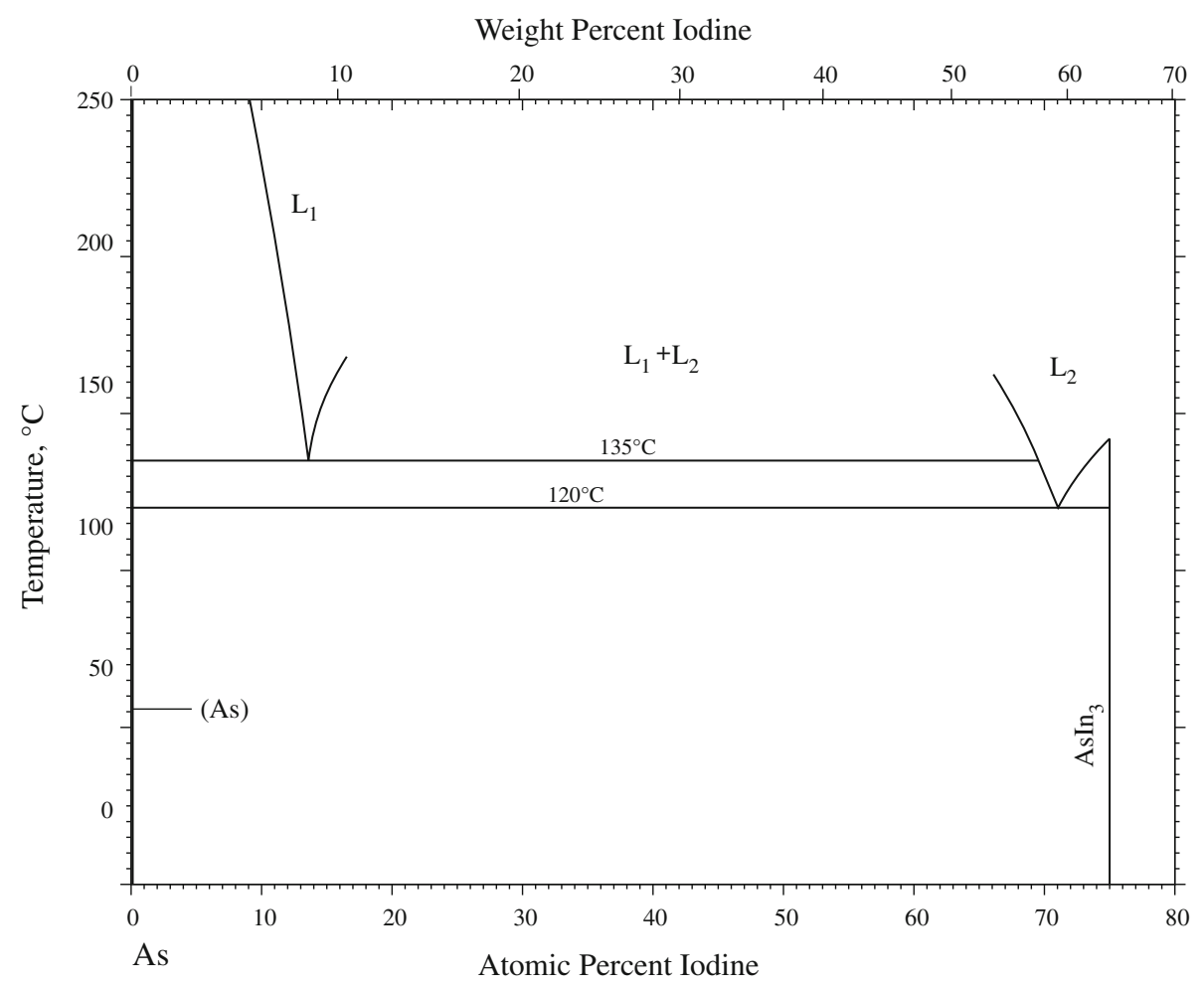

Fig. 1 As-I phase diagram 